\title{
Triple negative breast cancer and platinum- based systemic treatment: a meta-analysis and systematic review
}

\author{
Jessa Gilda P. Pandy ${ }^{*}$, Joanmarie C. Balolong-Garcia, Mel Valerie B. Cruz-Ordinario and Frances Victoria F. Que
}

\begin{abstract}
Background: Triple negative breast cancer (TNBC) represents $15-20 \%$ of breast cancers. Due to its heterogeneity and high rates of relapse, there is a need to optimize treatment efficacy. Platinum chemotherapy is still controversial and currently not recommended as first-line treatment for TNBC. Recent studies have shown promising activity of this regimen. This study was done to evaluate the effect of platinum chemotherapy on pathologic complete response ( $\mathrm{pCR}$ ) after neoadjuvant treatment for early TNBC and progression-free survival (PFS) in metastatic TNBC.

Methods: A systematic search of Pubmed, Embase, Cochrane, Clinical trials databases and hand search were done to identify randomized controlled trials (RCTs) investigating the use of platinum-based chemotherapy in adults with TNBC. Studies were appraised using the Cochrane Collaboration tool. Using the random effects model, pooled Odds ratios (ORs) with 95\% confidence intervals (Cl) for pCR, and Hazard Ratios (HRs) with 95\%Cl for PFS were analyzed.

Results: Eleven RCTs were included ( $N=2946)$. Platinum-based chemotherapy showed pCR benefit of $40 \%$ vs $27 \%$ (OR1.75,95\% Cl 1.46-2.62,p<0.0001) in the neo-adjuvant setting. Subgroup analysis showed increased pCR rates $(44.6 \%$ vs $27.8 \%)$ with platinum plus taxane regimen $(p<0.0001)$. In metastatic TNBC, three RCTs were analyzed $(N=$ 531), platinum treatment did not show PFS advantage (HR1.16,95\% Cl 0.90-1.49, $p=0.24$ ).

Conclusion: Platinum chemotherapy is associated with increased pCR rates in TNBC, hence it is a viable option for patients in the neoadjuvant setting. Subgroup analysis showed that the combination of platinum and taxanes (Carboplatin/Paclitaxel) improved pCR. However, no PFS advantage was seen in metastatic TNBC. Given the current conflicting data in metastatic TNBC, further exploration with additional powered studies is needed.
\end{abstract}

Keywords: Triple negative breast cancer, Platinum chemotherapy

\section{Background}

Breast cancer is the most frequent malignancy among women worldwide. Approximately $10-20 \%$ of breast cancer cases is defined by the lack of expression of targetable biomarkers such as hormone receptors and human epidermal growth factor receptor 2 (Her2/neu) [1]. This subset of breast cancer is known as triple-negative breast cancer (TNBC). TNBC is one of the most aggressive subtypes of breast cancer, posing a treatment challenge. It is usually associated with larger tumor size,

\footnotetext{
* Correspondence: jgpacispandy@gmail.com

Section of Medical Oncology, Cancer Institute, St. Luke's Medical Center, 279 E Rodriguez Sr. Ave, 1112 Quezon City, Metro Manila, Philippines
}

higher grade, and frequent nodal involvement [2]. Due to these characteristics, as many as $50 \%$ of patients diagnosed with early-stage triple-negative breast cancer experience disease recurrence, and $37 \%$ die in the first 5 years after surgery [3].

Whether in the early or advanced stages, chemotherapy represents the most widely accepted treatment for TNBC. The benefit of neo-adjuvant chemotherapy among TNBC has been evaluated in several trials. The GeparSixto trial in 2012 showed that neoadjuvant chemotherapy, using carboplatin, among TNBC and Her2-positive cases resulted in higher rates of pCR favoring TNBC (53\% vs 33\%) [4]. TNBC who attain pCR

(c) The Author(s). 2019 Open Access This article is distributed under the terms of the Creative Commons Attribution 4.0 International License (http://creativecommons.org/licenses/by/4.0/), which permits unrestricted use, distribution, and 
have improved event-free survival and overall survival, based on the CTNeoBC study in 2014, such that pCR may be used to convey prognostic information among this subset of patients [5].

In the most recent National Comprehensive Cancer Network (NCCN) guidelines [6], TNBC are treated with a combination of taxane- and anthracycline-based regimens. The benefit of taxane and anthracycline combination was compared to non-anthracycline regimen in the ABC Trials in 2017 which showed that in TNBC (31\% of total patients) the hazard ratio $(1.4295 \% \mathrm{CI}, 0.97$ to 1.49) was in favor of the anthracycline regimen [7]. The current guidelines endorse the same protocol, however, due to the heterogeneity and high rates of relapse of TNBC, there is a need to optimize treatment efficacy, and develop novel chemotherapeutic regimens that can potentially improve survival outcomes [8].

TNBC commonly harbors BRCA gene mutations that make them especially susceptible to to DNA-damaging compounds such as platinum drugs [9]. Several neoadjuvant clinical trials have evaluated the impact of adding platinum to standard chemotherapy. An early phase 2 trial by Silver et al. in 2010 [10], showed a pCR rate of $22 \%$ among all TNBC patients given neoadjuvant cisplatin. The GeparSixto trial by von Minckwitz et al. in 2014 [4], which included stage II or III TNBC $(n=588)$, demonstrated significant improvement in $\mathrm{pCR}$ with carboplatin $(p=0.005)$. However, the toxicities in the carboplatin arm caused a significantly higher rate of treatment discontinuation compared to the no carboplatin arm. In the CALGB 40603 trial by Sikov et al. in 2015, early TNBC patients showed higher pCR rates with the addition of carboplatin to the chemotherapy $(p=0.0089)$ [11]. To date, more recent trials have also investigated the role of platinum agents in TNBC, however the results are conflicting and studies are not powered enough to show statistically significant difference due to small populations [12].

Platinum chemotherapy has also been evaluated among TNBC in the metastatic setting. Currently, the 4th ESMO guidelines [13] recommend anthracyclinetaxane chemotherapy as first line for treatment of advanced TNBC, while carboplatin may be considered for BRCA positive TNBC as second line treatment [14]. Existing studies have shown conflicting results for the use of platinum agents as first-line treatment for metastatic TNBC. In a retrospective cohort study by Zhang et al. in 2015 [15], longer PFS was observed in metastatic TNBC patients receiving platinum-based chemotherapy compared with nonplatinum-based therapy in the first line metastatic setting $(7.8$ months vs. 4.9 months, $p<$ 0.001). Carey et al. in 2012 [16], showed in a randomized trial with metastatic TNBC patients, that combination cetuximab and carboplatin produced response rates in only less than $20 \%$ of patients. On the other hand, the CBCSG006 trial in 2015 by $\mathrm{Hu}$ et al. [17], showed increased PFS in patients with metastatic TNBC receiving cisplatin plus gemcitabine compared to patients receiving paclitaxel plus gemcitabine (7.73 vs 6.47 months, 95\% CI 6.16-9.30). This suggests that platinum chemotherapy could be an alternative first-line chemotherapy in metastatic TNBC.

With the results of existing studies using platinumbased chemotherapy for TNBC, we hypothesize that this treatment can be considered as a potential component of both the neoadjuvant chemotherapy among early TNBC patients and as first-line chemotherapy for metastatic TNBC patients. Current breast cancer guidelines [6] do not have a firm recommendation regarding use of platinum in either setting outside a clinical trial setting. This present study has been conducted to provide upto-date evidence on this topic and to provide a pooled analysis of existing results in order to further clarify the role of platinum-based chemotherapy in early and metastatic TNBC patients. The results of this study are deemed to aid in recommending platinum-based chemotherapy for TNBC patients.

\section{Methods}

\section{Literature search strategy and study identification}

Eligible studies were identified by a systematic literature search of Pubmed, Embase, and Cochrane databases and the clinical trials registry using the date limits January 2006 and July 2018 (Fig. 1). A thorough hand-search through the references of selected studies was also conducted for any additional relevant studies. There were no language restrictions. The keywords used in the search strategy were 'triple-negative', 'breast cancer', 'platinum' and 'chemotherapy'. Specific keywords and free text terms were combined with Boolean operators. The abstracts of the resulting studies were reviewed and full-text manuscripts were retrieved.

Resulting studies were selected and their eligibility was confirmed by three independent investigators. The systematic literature search was carried out independently by two authors (JP and MO) and any discrepancies were solved by discussion with a third author (JB).

\section{Selection criteria}

Eligible studies had to satisfy the following inclusion criteria: [1] randomized controlled trials (RCTs), [9] Adult (18 years and above) TNBC patients, [3] treatment with platinum-based neoadjuvant chemotherapy in the experimental arm and platinum-free neoadjuvant chemotherapy in the control arm, [8] had pCR or PFS as outcomes. Studies excluded were those with [1] incomplete data on treatment and ER/PR/Her2 status, [9] non- 


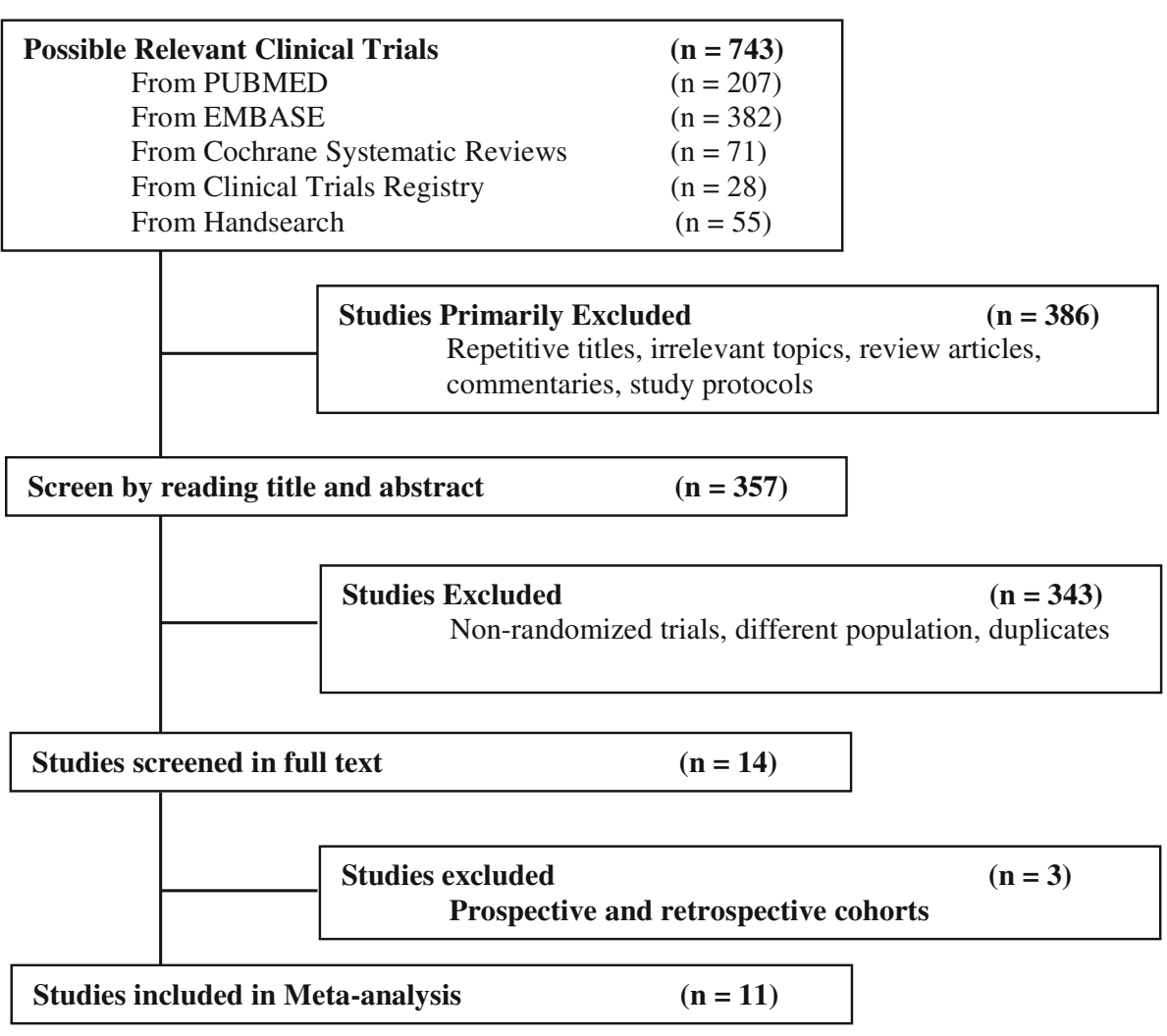

Fig. 1 Flow-chart of the literature search

RCTs, [3] RCTs involving other breast cancer subtypes, [8] and ongoing studies.

\section{Data extraction}

The following information was extracted from each study: authors' names, year of publication, study type, the total number of patients and chemotherapy regimens, type and dose of chemotherapy given, number of patients with pCR (defined as no residual invasive tumor in both the breast and the axilla, i.e. ypT0/is pN0) and PFS (defined as progression of disease from time of randomization) in the platinum-based and platinum-free chemotherapy arm.

\section{Quality evaluation}

The collated evidence was evaluated using the Cochrane Collaboration tool [18]. Accordingly, the quality of each study was graded as A, B or C.

\section{Statistical analysis}

Meta-analysis was conducted using Review Manager software (RevMan, version 5.3 for Windows; Cochrane Collaboration, Oxford, UK). The odds ratio (OR) and 95\% confidence interval (95\% CI) were calculated for the effect on pCR. Hazard ratios (HRs) and 95\% CI were calculated for the effect of platinum-based versus platinum- free neoadjuvant chemotherapy in terms of PFS. A $x^{2}$ test was used to evaluate heterogeneity in the data. The random-effects model was used. To obtain a quantitative measure of the degree of inconsistency in the results of the studies, the Higgins $\mathrm{I}^{2}$ index was computed. $\mathrm{I}^{2}$ values 0-40\% mean mild or non-significant heterogeneity; $30-$ $60 \%$ may represent moderate heterogeneity; 50-90\% represent substantial heterogeneity; and 90-100\% represent considerable heterogeneity. Funnel plots were generated using RevMan to detect publication bias.

\section{Study objectives}

The primary objective of this study is to compare the efficacy of platinum-based versus platinum-free chemotherapy in TNBC, specifically pCR among those who received neoadjuvant chemotherapy and PFS among those who received chemotherapy in the metastatic setting.

\section{Results}

Study selection and characteristics

A total of 743 articles were first identified for evaluation. Based on the inclusion and exclusion criteria described, 11 articles with 2946 patients were eligible for the meta-analysis. The search process is described 
Table 1 Characteristics of eligible studies

\begin{tabular}{|c|c|c|c|c|c|c|}
\hline Study & Year & Type & Population & Platinum-based regimen & Nonplatinum regimen & Outcomes \\
\hline $\begin{array}{l}\text { GEICAM/2006-03 } \\
\text { [19] }\end{array}$ & 2012 & $\begin{array}{l}\text { Randomized phase } 2 \\
\text { trial }\end{array}$ & TNBC & $\mathrm{EC} \times 4 \rightarrow \mathrm{DCb} \times 4$ cycles & $\mathrm{EC} \times 4 \rightarrow \mathrm{D} \times 4$ cycles & $\begin{array}{l}\text { pCR: } \\
\text { EC-D } 35 \% \\
\text { EC-DCb } 45 \% \\
(p=0.606)\end{array}$ \\
\hline Ando [20] & 2014 & $\begin{array}{l}\text { Randomized phase } 2 \\
\text { trial }\end{array}$ & TNBC & CP q wk. $\times 12 \rightarrow$ CEF $\times 4$ cycles & $\begin{array}{l}\text { P q wk. } \times 12 \rightarrow \text { CEF } \times 4 \\
\text { cycles }\end{array}$ & $\begin{array}{l}\text { PCR: } \\
\text { CP-CEF } 31.8 \% \\
\text { P-CEF } 17.6 \% \\
(p=0.01)\end{array}$ \\
\hline $\begin{array}{l}\text { WSG-ADAPT-TN } \\
{[21]}\end{array}$ & 2017 & $\begin{array}{l}\text { Randomized phase } 2 \\
\text { trial }\end{array}$ & TNBC & $\begin{array}{l}\mathrm{Nab}-\mathrm{P} / \\
\mathrm{Cb} \times 4\end{array}$ & Nab-P/ Gem × 4 & $\begin{array}{l}\frac{\mathrm{pCR}}{\mathrm{Nab}-\mathrm{P}-\mathrm{Cb}} \\
45.9 \% \\
\text { Nab-P-Gem } \\
28.7 \% \\
p=0.002\end{array}$ \\
\hline $\begin{array}{l}\text { BrighT } \\
\text { Ness [22] }\end{array}$ & 2018 & $\begin{array}{l}\text { Randomized phase } 3 \\
\text { trial }\end{array}$ & TNBC & $\begin{array}{l}\text { Arm 1: PCb }+ \text { Veliparib } \times 4 \text { cycles } \\
\text { Arm 2: PCb }+ \text { Veliparib placebo } \times \\
4 \text { cycles }\end{array}$ & $\begin{array}{l}\text { Arm 3: Paclitaxel + Carboplatin } \\
\text { placebo + Veliparib placebo } \times \\
4 \text { cycles }\end{array}$ & $\begin{array}{l}\frac{\mathrm{pCR}}{\text { Arm } 153 \%} \\
\text { Arm } 258 \% \\
\text { Arm } 331 \%\end{array}$ \\
\hline CALGB 40603 [11] & 2015 & $\begin{array}{l}\text { Randomized phase } 2 \\
\text { trial }\end{array}$ & TNBC & $\begin{array}{l}\text { Arm 3: } P \times 12 w+C b \times 4 \rightarrow \\
d d A C \times 4 \\
\text { Arm 4: } P \times 12 w+C b \times 4+ \\
\text { Bev } \times 9 \rightarrow d d A C \times 4\end{array}$ & $\begin{array}{l}\text { Arm 1: } P \times 12 w \rightarrow d d A C \times 4 \\
\text { Arm 2: } P \times 12 w+B e v q 2 w \times \\
9 w \rightarrow d d A C \times 4\end{array}$ & $\begin{array}{l}\frac{\mathrm{pCR}}{(+)} \mathrm{Cb} 60 \% \\
(-) \text { Cb } 46 \% \\
\text { (+) Bev 59\% } \\
\text { (-) Bev 48\% }\end{array}$ \\
\hline TNT Trial [23] & 2018 & $\begin{array}{l}\text { Randomized phase } 3 \\
\text { trial }\end{array}$ & TNBC & $\mathrm{Cb}$ & D & $\begin{array}{l}\frac{p C R}{C b 6.7 \%} \\
\text { D } 3.3 \%\end{array}$ \\
\hline $\begin{array}{l}\text { Gepar } \\
\text { Sixto [4] }\end{array}$ & 2014 & $\begin{array}{l}\text { Randomized phase } 2 \\
\text { trial }\end{array}$ & TNBC & $\begin{array}{l}\mathrm{Cb}+\mathrm{PDB} \times 18 \mathrm{w} \text { or } \mathrm{Cb}+ \\
\mathrm{PDH} \times 18 \mathrm{w}\end{array}$ & $\mathrm{PDB} \times 18 \mathrm{w}$ or $\mathrm{PDH} \times 18 \mathrm{w}$ & $\begin{array}{l}\frac{\mathrm{pCR}}{(+) C b} 43.7 \% \\
(-) \text { Cb } 36.9 \%\end{array}$ \\
\hline Zhang [24] & 2016 & $\begin{array}{l}\text { Randomized phase } 2 \\
\text { trial }\end{array}$ & TNBC & $\mathrm{PCb}$ & EP & $\begin{array}{l}\frac{\mathrm{pCR}}{\mathrm{PCb}} 38.6 \% \\
\mathrm{EP} 14.0 \%\end{array}$ \\
\hline CBCSG006 [17] & 2015 & $\begin{array}{l}\text { Randomized phase } 3 \\
\text { trial }\end{array}$ & $\begin{array}{l}\text { Metastatic } \\
\text { TNBC }\end{array}$ & Gemcitabine/ Cisplatin $\times 8$ cycles & $\begin{array}{l}\text { Gemcitabine / Paclitaxel } \times \\
8 \text { cycles }\end{array}$ & $\begin{array}{l}\frac{\mathrm{OS}}{\mathrm{Ge}} / \mathrm{Cis} \times 8 \\
59 \% \\
\mathrm{Gem} / \mathrm{P} \times 8 \\
58 \% \\
\mathrm{p}=0.611\end{array}$ \\
\hline Carey [16] & 2012 & $\begin{array}{l}\text { Randomized phase } 2 \\
\text { trial }\end{array}$ & $\begin{array}{l}\text { Metastatic } \\
\text { TNBC }\end{array}$ & $\mathrm{Cet} / \mathrm{Cb}$ & Cet & $\begin{array}{l}\text { PFS: } \\
\text { Cet }+ \text { Cb } 77 \% \\
\text { Cb } 97 \% \\
\text { OS: } \\
\text { Cet }+ \text { Cb } 83 \% \\
\text { Cb 83\% }\end{array}$ \\
\hline Fan [25] & 2012 & $\begin{array}{l}\text { Randomized phase } 2 \\
\text { trial }\end{array}$ & $\begin{array}{l}\text { Metastatic } \\
\text { TNBC }\end{array}$ & $\mathrm{DP} \times 6$ cycles & DX $\times 6$ cycles & $\begin{array}{l}\text { PFS: } \\
\text { TP 25\% } \\
\text { TX 10\% } \\
\text { p < } 0.001 \\
\text { OS } \\
\text { TP } 28 \% \\
\text { TX } 10 \% \\
\text { p }=0.02\end{array}$ \\
\hline
\end{tabular}

$[p C R=$ pathological complete response; $D F S=$ Disease free survival; $C R R=$ Complete response rate; $O S=$ Overall survival; $R R=$ Response rate; $E=E$ Eirubin; $C / C b=$ Carboplatin; $D=$ Docetaxel; $C E F=$ Cyclophosphamide/Epirubicin/5-Fluorouracil; $P=$ Paclitaxel; Cet $=$ Cetuximab; $D P=$ Docetaxel $/ C$ isplatin $D X=$ Docetaxel/ Capecitabine; Nab-P = Nab-Paclitaxel; Gem = Gemcitabine; $d d A C$ Doxorubicin/Cyclphosphamide; Bev = Bevacizumab; $H=$ Trastuzumab]

in Fig. 1. Table 1 shows the characteristics of the included studies.

Eleven randomized controlled trials were included in this study $(N=2946)$. Eight studies $(N=2415)$ which administered platinum-based neoadjuvant treatment were included for analysis of $\mathrm{pCR}$ and three studies $(N=531)$ which included metastatic TNBC were analyzed for PFS. 


\section{Risk of bias assessment}

Risk of bias assessment is summarized in Table 2. Using the Cochrane risk of bias assessment tool ${ }^{22}$, one study by Loibl et al. was graded $\mathrm{A}$, while all the others were graded $B$ primarily due to the lack of patient and staff blinding in these studies.

\section{$p C R$ rates of TNBC patients treated with neoadjuvant platinum- versus non-platinum-based regimen}

Eight studies $(N=2415)$ reported pCR rates in TNBC patients. Figure 2 showed a statistically significant improved $\mathrm{pCR}$ rate $(P<0.0001)$ among patients treated with a platinum-based regimen than among those treated with a non-platinum-based regimen $(40.1 \%$ vs 27.7\%; OR, 1.75; 95\% CI, 1.36-2.26). Trials have moderate heterogeneity $\left(\mathrm{I}^{2}=40 \%\right)$ and evaluation with random effects model was done. The funnel plot (Fig. 5) generated showed mild asymmetry.

In all eight studies, Carboplatin was added as the platinum agent to an anthracycline- and taxane-based neoadjuvant chemotherapy. The study by Loibl $^{16}$ used Paclitaxel with Veliparib, a PARP inhibitor, with or without Carboplatin while the studies by Sikov ${ }^{14}$ and Von Minckwitz ${ }^{9}$, both phase II RCTs added an anti-VEGF, Bevacizumab, to the chemotherapy regimen.

\section{Subgroup analysis of $p C R$ rates among TNBC patients treated with neoadjuvant platinum-based regimen}

Subgroup analysis was done to remove heterogeneity among the trials, which may be attributed to the type of chemotherapy agent combined with platinum. Two subgroups were analyzed: platinum + taxane regimen and platinum + anthracycline regimen.

Three [3] studies have platinum + taxane regimen $(N=$ 590). As seen in Fig. 3, the pooled analysis showed statistically significant increase in pCR rates $(44.6 \%$ vs $27.8 \%)$ among TNBC patients treated with a taxane (Paclitaxel) plus a platinum agent (Carboplatin) using random effects model ( $p$ value $<0.0001)$. With an $\mathrm{I}^{2}$ of 0 , results of the three studies were homogenous. The second subgroup with two studies with platinum and anthracycline regimen, did not show any significant benefit.

\section{PFS rates among metastatic TNBC patients treated with a platinum- or a non-platinum-based regimen}

Three studies $(N=531)$ evaluated the PFS rates among TNBC patients. Figure 4 showed that the difference in PFS rates was not statistically significant $(P=0.24)$ among those treated with platinum-based regimen compared to those treated with non-platinum based regimen. Studies and results were homogenous with an $\mathrm{I}^{2}$ of 0

\section{Safety profile}

In both neoadjuvant and metastatic settings, toxic effects such as anaemia, neutropenia, thrombocytopenia, and nausea, occurred more commonly in the group given platinum. The addition of platinum was also associated with a higher rate of diarrhoea and anorexia. On the other hand, skin rash, nail changes, pneumonitis, and other cardiac disorders were more common in the group not treated with platinum. Patients assigned to the platinum arm were more likely to require dose reduction or stop treatment early because of toxicity.

\section{Discussion}

Despite progress, TNBC still has significantly lower responses to therapy compared to other molecular subtypes of breast cancer. Several factors hinder treatment of TNBC, such as: a high tendency to metastasize to other organ sites, lack of FDA-approved targeted therapies, high rates of recurrence after diagnosis, and extreme heterogeneity of TNBCs [2].

Table 2 Risk of Bias Summary using the Cochrane Collaboration's Tool

\begin{tabular}{llllll}
\hline Study & Selection & Performance & Exclusion & Detection & Quality \\
\hline Alba 2012 & B & B & B & B & B \\
Ando 2014 & B & B & A & B & B \\
Carey 2012 & B & B & A & B & B \\
Fan 2012 & B & B & A & B & B \\
Gluz 2017 & B & B & B & B & B \\
Hu 2015 & A & B & A & B & B \\
Loibl 2018 & A & A & A & A & A \\
Sikov 2015 & B & B & B & B & B \\
Tutt 2018 & A & B & A & B & B \\
Von Minkwitz 2014 & B & B & A & B & B \\
Zhang 2016 & B & B & A & B & B \\
\hline
\end{tabular}




\begin{tabular}{|c|c|c|c|c|c|c|c|}
\hline \multirow[b]{2}{*}{ Study or Subgroup } & \multicolumn{2}{|c|}{ Platinum } & \multicolumn{2}{|c|}{ Non-platinum } & \multirow[b]{2}{*}{ Weight } & \multirow{2}{*}{$\begin{array}{c}\text { Odds Ratio } \\
\mathrm{M}-\mathrm{H} \text {, Random, } 95 \% \mathrm{Cl}\end{array}$} & \multirow{2}{*}{$\begin{array}{c}\text { Odds Ratio } \\
\text { M-H, Random, } 95 \% \mathrm{Cl} \\
\end{array}$} \\
\hline & PCR & Total & PCR & Total & & & \\
\hline Alba 2012 & 16 & 47 & 15 & 46 & $6.9 \%$ & $1.07[0.45,2.53]$ & \\
\hline Ando 2014 & 40 & 88 & 30 & 91 & $11.5 \%$ & $1.69[0.92,3.11]$ & \\
\hline Gluz 2017 & 67 & 146 & 51 & 178 & $16.1 \%$ & $2.11[1.33,3.35]$ & \\
\hline Loibl 2018 & 168 & 316 & 49 & 159 & $18.3 \%$ & $2.55[1.70,3.81]$ & \\
\hline Sikov 2015 & 60 & 221 & 46 & 212 & $16.8 \%$ & $1.34[0.87,2.09]$ & \\
\hline Tutt 2018 & 8 & 118 & 4 & 118 & $3.8 \%$ & $2.07[0.61,7.08]$ & \\
\hline Von Minckwitz 2014 & 136 & 295 & 115 & 293 & $21.8 \%$ & $1.32[0.95,1.84]$ & \\
\hline Zhang 2016 & 17 & 44 & 6 & 43 & $4.9 \%$ & $3.88[1.35,11.15]$ & \\
\hline Total $(95 \% \mathrm{Cl})$ & & 1275 & & 1140 & $100.0 \%$ & $1.75[1.36,2.26]$ & \\
\hline Total PCR & 512 & & 316 & & & & \\
\hline $\begin{array}{l}\text { Heterogeneity: } \text { Tau }^{2}= \\
\text { Test for overall effect }\end{array}$ & $\begin{array}{l}05: \mathrm{Ch}^{2} \\
=4.36(\mathrm{~F}\end{array}$ & $\begin{array}{l}=11.6 \\
0<0.00\end{array}$ & 3, df = 7( & $0.11)$ & $I^{2}=40 \%$ & & $\begin{array}{cccc}0.5 & 0.7 & 1 & 1.5 \\
\text { Non-platinum } & \text { Platinum }\end{array}$ \\
\hline
\end{tabular}

Fig. 2 Forest plot showing pooled incidence of pCR in platinum vs non-platinum chemotherapy in early TNBC patients using random effects model with $95 \%$ confidence interval

The response to neo-adjuvant chemotherapy varies with breast cancer molecular subtype. Studies have shown that both TNBC and Her2-positive breast cancer have excellent prognosis once pCR is achieved after neoadjuvant chemotherapy compared to other molecular subtypes [9]. There are six subtypes of TNBC based on molecular sub-typing and gene expression studies. These include: basal-like-1, basal-like-2, immune-modulatory, mesenchymal, mesenchymal-like and a luminal androgen receptor subtype [3]. Among the subtypes, $75 \%$ are basal-like and these are most commonly associated with BRCA1 mutations. Platinum compounds are found to be

\begin{tabular}{|c|c|c|c|c|c|c|}
\hline \multirow[b]{2}{*}{ Study or Subgroup } & \multicolumn{2}{|c|}{ Carboulatin + Paclitaxel } & \multicolumn{2}{|c|}{ Nonblatinum } & \multirow{2}{*}{$\begin{array}{c}\text { Odds Ratio } \\
\text { M.H, Random, } 95 \% \mathrm{Cl}\end{array}$} & \multirow{2}{*}{$\begin{array}{c}\text { Odds Ratio } \\
\text { M.H, Random, } 95 \% \mathrm{Cl}\end{array}$} \\
\hline & PCR & Total & PCR & Total Weight 1 & & \\
\hline Ando 2014 & 40 & 88 & 30 & $91 \quad 32.6 \%$ & $1.69[0.92,3.11]$ & \\
\hline Gluz 2017 & 67 & 146 & 51 & $178 \quad 56.6 \%$ & $2.11[1.33,3.35]$ & \\
\hline Zhang 2016 & 17 & 44 & 6 & $43 \quad 10.8 \%$ & $3.88[1.35,11.15]$ & \\
\hline \multicolumn{2}{|l|}{ Total $(95 \% \mathrm{Cl})$} & 278 & & $312 \quad 100.0 \%$ & $2.10[1.48,2.97]$ & \\
\hline Total PCR & 124 & & 87 & & & \\
\hline \multicolumn{5}{|c|}{$\begin{array}{l}\text { Heterogeneity: Tau }{ }^{2}=0.00 ; \mathrm{Chi}^{2}=1.79, \mathrm{df}=2(\mathrm{P}=0.41) ; \mathrm{I}^{2}=0 \% \\
\text { Test for overall effect: } Z=4.20(\mathrm{P}<0.0001)\end{array}$} & & $\begin{array}{ccccc}0.5 & 0.7 & 1 & 1.5 & 2 \\
\text { Nonplatinum } & \text { Carboplatin + Paclitaxel }\end{array}$ \\
\hline \multirow[b]{2}{*}{ Study or Subgroup } & \multicolumn{2}{|c|}{ Platinum + Anthracy cline } & \multicolumn{2}{|c|}{ Non-platinum } & Odds Ratio & \multirow{2}{*}{$\begin{array}{c}\text { Odds Ratio } \\
\text { MH, Random, } 95 \% \mathrm{Cl}\end{array}$} \\
\hline & PCR & Total & PCR & Total Weight & MH, Random, $95 \% \mathrm{Cl}$ & \\
\hline Alba 2012 & 16 & 47 & 15 & $46 \quad 12.6 \%$ & $1.07[0.45,2.53]$ & \\
\hline Von Minckwit 2014 & 136 & 295 & 115 & $29387.4 \%$ & $1.32[0.95,1.84]$ & \\
\hline Total $(95 \% \mathrm{Cl})$ & & 342 & & $339 \quad 100.0 \%$ & $1.29[0.95,1.75]$ & \\
\hline Total PCR & 152 & & 130 & & & \\
\hline $\begin{array}{l}\text { Heterogeneity: Tau }{ }^{2}= \\
\text { Test for overall effect: }\end{array}$ & $\begin{array}{l}0.00 ; \mathrm{Chi}^{2}=0.2 \\
Z=1.62(P=0 .\end{array}$ & $=1(P=0$. & $.65) ; 1^{2}=0$ & & & $\begin{array}{ccccc}0.5 & 0.7 & 1 & 1.5 & 2 \\
& \text { Non-platinum } & \text { Platinum }\end{array}$ \\
\hline
\end{tabular}




\begin{tabular}{|c|c|c|c|c|c|}
\hline Study or Subgroup & log[Hazard Ratio] & SE & Weight & $\begin{array}{c}\text { Hazard Ratio } \\
\text { IV, Random, } 95 \% \mathrm{CI}\end{array}$ & $\begin{array}{c}\text { Hazard Ratio } \\
\text { IV, Random, } 95 \% \mathrm{Cl} \\
\end{array}$ \\
\hline Carey 2012 & 0.09 & 0.219 & $34.2 \%$ & $1.09[0.71,1.68]$ & 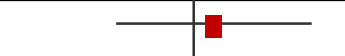 \\
\hline Fan 2012 & 0.53 & 0.548 & $5.5 \%$ & $1.70[0.58,4.97]$ & \\
\hline Hu 2015 & 0.15 & 0.165 & $60.3 \%$ & $1.16[0.84,1.61]$ & \\
\hline Total $(95 \% \mathrm{Cl})$ & & & $100.0 \%$ & $1.16[0.90,1.49]$ & \\
\hline \multicolumn{6}{|c|}{ 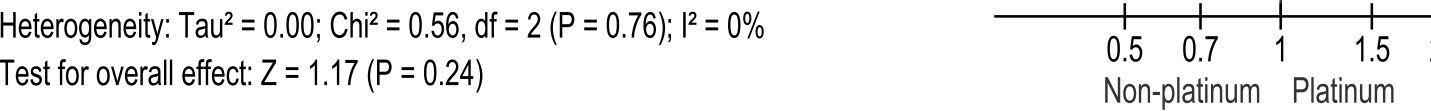 } \\
\hline
\end{tabular}

Fig. 4 Forest plot showing pooled Hazard ratios in platinum vs non-platinum chemotherapy in metastatic TNBC using random effects model with $95 \%$ confidence interval

especially useful in cancer cells with deficiencies in DNA repair such as those with BRCA gene mutations, due to the formation of platinum-DNA adducts. The TNT phase III trial randomized 376 patients with metastatic TNBC to docetaxel or carboplatin. In the BRCA mutation carriers $(n=29)$ response rates to carboplatin were $68 \%$ compared to $30 \%$ for docetaxel [23]. It is therefore warranted to investigate this relationship between BRCA mutation and chemo-sensitivity.

The benefit of neoadjuvant chemotherapy among TNBC shown in our results is consistent with current recommendations. Among the 2415 TNBC patients who underwent platinum-based neoadjuvant chemotherapy, this study showed statistically significant improvement in $\mathrm{pCR}$ rates compared to non-platinumbased treatment. However, this data is affected by moderate heterogeneity among the studies, which has been associated with the varied agents combined with the platinum therapy. It remains unclear how platinum should be incorporated and whether concomitant use of platinum could be used to substitute for anthracycline, taxane or an alkylator. Subgroup analyses of the neoadjuvant platinum-based regimen showed that platinum combined with taxane has statistically significant improved pCR. This is consistent with the BrightTNess trial [22] in 2018 which showed that combination of carboplatin and paclitaxel increased $\mathrm{pCR}$ rates.

Platinum-containing agents are not regarded as a standard for neoadjuvant therapy of TNBC, for several reasons. One reason is that given that the addition of platinum results in greater toxicity as seen in the previous studies, the clinical benefits of its use should be clear. It is also possible that the improvements in $\mathrm{pCR}$ rates may be a result of down staging of low-volume residual disease, which is not known to translate to lower recurrence rates. In addition, pCR may not be associated with improved outcomes in BRCA1/2 mutation carriers, suggesting the inconsistency of its prognostic effect.

In the metastatic setting, this metanalysis did not show any advantage in terms of PFS among TNBC patients. Platinum-based chemotherapy has been suggested to potentially be more effective than non-platinum-based chemotherapy in metastatic TNBC. In the CBCSG006 trial by $\mathrm{Hu}$ et al. [17], where Gemcitabine was used as the backbone, Cisplatin was compared to Paclitaxel as a first line metastatic treatment. Over-all response rate was higher in Cisplatin-Gemcitabine combination than in Paclitaxel-Gemcitabine (64\% vs $49 \%, p<0.018$ ) with a PFS advantage of 1.26 months (HR 0.692, 95\% CI 6.199.30, $p<0.0001)$. No overall survival difference was noted. However, several limitations were noted in this particular study including potential bias in the definition of TNBC and financial limitations which preclude central assessment, and further classification into TNBC subtypes.

The TBCRC 001 trial divided the study cohorts into three arms and investigated Cetuximab with or without Carboplatin. Expression of Epidermal Growth Factor Receptor (EGFR), a key gene in the basal-like TNBC, was assessed. However, the limited activity of Cetuximab shown in this study by Carey et al. [16]. suggests that TNBC may have constitutive pathway activation via downstream components such as KRAS amplification or CRYAB expression. The study by Fan et al. [25], with a Taxane-based treatment compared Cisplatin (TP) and Capecitabine (TX). Regardless of the metastasis, the response rates were noted to be higher in the TP arm than in the TX arm $(63 \%$ vs $15.4 \%, P=0.001)$. Median PFS and Median OS were also statistically longer in the TP arm.

The current conflicting data using platinum among TNBC patients in the metastatic setting may not be 


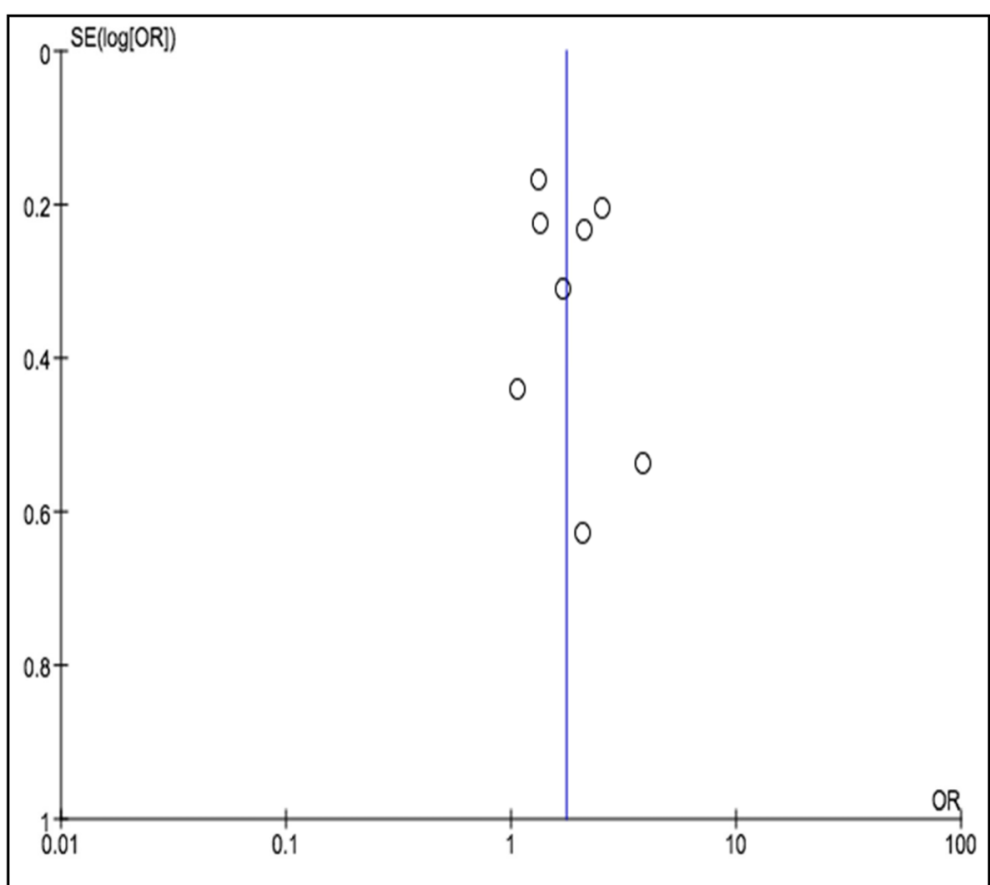

Fig. 5 Funnel plot of the pCR rate in TNBC patients who were treated with a platinum-or non-platinum-based regimen

sufficient to warrant further study, however, the potential of platinum therapy in certain subtypes of TNBC may be explored further.

\section{Conclusion}

Platinum-based systemic treatment is associated with statistically significant improved pCR rates among patients with TNBC in the neoadjuvant setting. Subgroup analysis of homogenous data further delineated that the combination of platinum and taxanes improved pCR rates in the same population. With these results, a platinum-taxane regimen may be a justifiable treatment regimen for operable TNBC. On the other hand, in the metastatic setting, platinum-based regimen did not show statistically significant advantage in PFS. BRCA1 mutation determination for all TNBC patients may cause a potential paradigm shift in the management of these type of patients in the future.

\section{Abbreviations \\ Cl: Confidence interval; DFS: Disease-free survival; DNA: Deoxyribonucleotide acid; HR: Hazard ratio; NCCN: National Comprehensive Cancer Network; OR: Odds ratio; ORR: Overall response rate; OS: Overall survival; pCR: Pathologic complete response; PFS: Progression-free survival; RCT: Randomized controlled trial; TNBC: Triple negative breast cancer}

\section{Acknowledgements}

Presented during the ESMO Asia 2018 Congress. Abstract available at: https:// oncologypro.esmo.org/Meeting-Resources/ESMO-Asia-2018-Congress/TripleNegative-Breast-Cancer-and-Platinum-based-Systemic-Treatment-Metaanalysis-and-Systematic-Review
Authors' contributions

JP, JBG, MO collected and processed the data from the studies, and performed data analysis. JP drafted the manuscript and designed the figures. JBG and MO contributed to the writing of the manuscript. FQ conceptualized the research, supervised the work, and contributed to the editing and wiritng of the final manuscript. All authors read and approved the final manuscript.

Authors' information

The authors are currently colleagues training at the Cancer Institute of St. Luke's Medical Center, Philippines.

\section{Funding}

The manuscript has not been supported by any source of support, including sponsorship or any financial sources.

\section{Availability of data and materials}

All data generated or analysed during this study are included in this published article and referenced articles are listed in the References section.

Ethics approval and consent to participate

Not applicable.

\section{Consent for publication}

Not applicable.

\section{Competing interests}

The authors declare that they have no competing interests.

Received: 25 April 2019 Accepted: 14 October 2019

Published online: 08 November 2019

\section{References}

1. Ahmed Wahba H, Ahmed El-Hadaad H. Current approaches in treatment of triple-negative breast cancer. Cancer Biol Med | v June | PMC4493381 Citations Cancer Biol Med. 2015. https://doi.org/10.7497/j.issn.2095-3941. 2015.0030.

2. DeVita VT, Hellman S, Rosenberg SA. DeVita, Hellman, and Rosenberg's Cancer principles \& practice of oncology review. 11th Ed. 2018. 
3. Berrada N, Delaloge $S$, André F. Treatment of triple-negative metastatic breast cancer: toward individualized targeted treatments or chemosensitization? In: Annals of Oncology. 2010. https://doi.org/10.1093/ annonc/mdq279.

4. Von Minckwitz G, Schneeweiss A, Loibl S, et al. Neoadjuvant carboplatin in patients with triple-negative and HER2-positive early breast cancer (GeparSixto; GBG 66): a randomised phase 2 trial. Lancet Oncol. 2014. https://doi.org/10.1016/S1470-2045(14)70160-3.

5. Cortazar $P$, Zhang L, Untch $M$, et al. Pathological complete response and long-term clinical benefit in breast cancer: the CTNeoBC pooled analysis. Lancet. 2014. https://doi.org/10.1016/S0140-6736(13)62422-8.

6. Goetz MP, Gradishar WJ, Anderson BO, et al. Breast cancer, version 3.2018 featured updates to the NCCN guidelines. JNCCN J Natl Compr Cancer Netw. 2019. https://doi.org/10.6004/jnccn.2019.0009.

7. Blum JL, Flynn PJ, Yothers G, et al. Anthracyclines in early breast Cancer: the ABC trials-USOR 06-090, NSABP B-46-I/USOR 07132, and NSABP B-49 (NRG oncology). J Clin Oncol. 2017. https://doi.org/10.1200/JCO.2016.71.4147.

8. Costa RLB, Gradishar WJ. Triple-negative breast Cancer: current practice and future directions. J Oncol Pract. 2017. https://doi.org/10.1200/jop.2017.023333.

9. Lehmann BD, Bauer JA, Schafer JM, et al. PIK3CA mutations in androgen receptor-positive triple negative breast cancer confer sensitivity to the combination of PI3K and androgen receptor inhibitors. Breast Cancer Res. 2014. https://doi.org/10.1186/s13058-014-0406-x.

10. Silver DP, Richardson AL, Eklund AC, et al. Efficacy of neoadjuvant cisplatin in triple-negative breast cancer. J Clin Oncol. 2010. https://doi.org/10.1200/ JCO.2009.22.4725.

11. Sikov WM, Berry DA, Perou CM, et al. Impact of the addition of carboplatin and/or bevacizumab to neoadjuvant once-per-week paclitaxel followed by dose-dense doxorubicin and cyclophosphamide on pathologic complete response rates in stage II to III triple-negative breast cancer: CALGB 40603 (Alliance). J Clin Oncol. 2015. https://doi.org/10.1200/JCO.2014.57.0572.

12. Tian $\mathrm{m}$, zhong $\mathrm{y}$, zhou $\mathrm{f}$, xie $\mathrm{c}$, zhou $\mathrm{y}$, liao z. Platinum-based therapy for triple-negative breast cancer treatment: A meta-analysis. Mol Clin Oncol. 2015. doi:https://doi.org/10.3892/mco.2015.518

13. Cardoso F, Senkus E, et al. 4th ESO-ESMO International Consensus Guidelines for Advanced Breast Cancer (ABC 4) Annals of Oncology, Volume 29, Issue 8, 1 August 2018, Pages 1634-1657.

14. Von Minckwitz G, Untch M, Blohmer JU, et al. Definition and impact of pathologic complete response on prognosis after neoadjuvant chemotherapy in various intrinsic breast cancer subtypes. J Clin Oncol. 2012. https://doi.org/10.1200/JCO.2011.38.8595.

15. Zhang J, Fan M, Xie J, et al. Chemotherapy of metastatic triple negative breast cancer: experience of using platinum-based chemotherapy. Oncotarget. 2015;6:43135-43.

16. Carey LA, Rugo HS, Marcom PK, et al. TBCRC 001: randomized phase II study of cetuximab in combination with carboplatin in stage IV triple-negative breast cancer. J Clin Oncol. 2012. https://doi.org/10.1200/JCO.2010.34.5579.

17. Hu XC, Zhang J, Xu BH, et al. Cisplatin plus gemcitabine versus paclitaxel plus gemcitabine as first-line therapy for metastatic triple-negative breast cancer (CBCSG006): a randomised, open-label, multicentre, phase 3 trial. Lancet Oncol. 2015. https://doi.org/10.1016/S1470-2045(15)70064-1.

18. Higgins J, Green S (editors). Cochrane Handbook for Systematic Reviews of Interventions Version 5.1.0.; 2011

19. Alba $\mathrm{E}$, Chacon Jl, Lluch $\mathrm{A}$, et al. A randomized phase II trial of platinum salts in basal-like breast cancer patients in the neoadjuvant setting. Results from the GEICAM/2006-03, multicenter study. Breast Cancer Res Treat. 2012. https://doi.org/10.1007/s10549-012-2100-y.

20. M. A, H. Y, K. A, et al. Randomized phase II study of weekly paclitaxel with and without carboplatin followed by cyclophosphamide/epirubicin/5fluorouracil as neoadjuvant chemotherapy for stage II/IIA breast cancer without HER2 overexpression. Breast Cancer Res Treat. 2014. doi:https://doi. org/10.1007/s10549-014-2947-1

21. O. G, U. N, C. L, et al. Comparison of neoadjuvant Nab-paclitaxel1 carboplatin vs nab-paclitaxel1gemcitabine in triple-negative breast cancer: Randomized WSG-ADAPT-TN trial results. J Natl Cancer Inst. 2018. doi:https://doi.org/10. 1093/jnci/djx258

22. Loibl S, O'Shaughnessy J, Untch M, et al. Addition of the PARP inhibitor veliparib plus carboplatin or carboplatin alone to standard neoadjuvant chemotherapy in triple-negative breast cancer (BrighTNess): a randomised, phase 3 trial. Lancet Oncol. 2018. https://doi.org/10.1016/S14702045(18)30111-6.
23. Tutt A, Tovey H, Cheang MCU, et al. Carboplatin in BRCA1/2-mutated and triple-negative breast cancer BRCAness subgroups: the TNT trial. Nat Med. 2018. https://doi.org/10.1038/s41591-018-0009-7.

24. Zhang $\mathrm{P}$, Yin $\mathrm{Y}, \mathrm{Mo} \mathrm{H}$, et al. Better pathologic complete response and relapse-free survival after carboplatin plus paclitaxel compared with epirubicin plus paclitaxel as neoadjuvant chemotherapy for locally advanced triple-negative breast cancer: a randomized phase 2 trial. Oncotarget. 2016. https://doi.org/10.18632/oncotarget.10607.

25. Fan $Y, X u B H$, Yuan $P$, et al. Docetaxel-cisplatin might be superior to docetaxel-capecitabine in the first-line treatment of metastatic triplenegative breast cancer. Ann Oncol. 2013. https://doi.org/10.1093/annonc/ mds603.

\section{Publisher's Note}

Springer Nature remains neutral with regard to jurisdictional claims in published maps and institutional affiliations.
Ready to submit your research? Choose BMC and benefit from:

- fast, convenient online submission

- thorough peer review by experienced researchers in your field

- rapid publication on acceptance

- support for research data, including large and complex data types

- gold Open Access which fosters wider collaboration and increased citations

- maximum visibility for your research: over $100 \mathrm{M}$ website views per year

At BMC, research is always in progress.

Learn more biomedcentral.com/submissions 